\title{
News from the international federation of robotics for robotica
}

\section{JAPAN}

New challenges face the robot industry of tomorrow. 'It is estimated that the Japanese robot industry increased its production to Yen550billion in 1997,' writes Seiuemon Inaba, Chairman of the Japan Robot Association in his New Year message. 'This is $17 \%$ up over the preceding year, due chiefly to the rapid recovery of exports, in addition to the active domestic demand that has continued since 1996. The figures also reflect a firm trend of capital investment. 'Although recent economic conditions have led to some uncertainties about future developments of the business climate, the industry's production in 1998 is likely to regain the Yen600billion level, an all-time high which was reached in the previous peak period,' he adds. 'In respect of the fundamental economic and social needs for robots in Japan, we believe it is essential to further development of the nation's manufacturing industry-based economy that steps are taken to meet the requirements of industry, particularly in the strengthening of its international competitive abilities through the improvement of productivity and the establishment of a more efficient production system,' writes $\mathrm{Mr}$ Inaba. 'In addition, the industry is called on to meet various other requirements, including measures to compensate for the shortage of skilled workers, the development of an intellectual, comfortable working environment to arrest the tendency of young workers to defect from the manufacturing sector, the release of workers from the so-called 'three-D (dangerous, dirty and difficult) jobs, and the reduction of working hours,' declares Mr Inaba. 'These requirements are expected to bring about mid-to-long-term active demand for automation equipment, especially robots and factory automation systems,' writes $\mathrm{Mr}$ Inaba. 'At present robots are used mostly in the conventional manufacturing industyr, but in the years ahead, their application will be expanded to the personal sector, covering household uses and support systems for the daily life of the elderly and handicapped, as well as to non-manufacturing industries, including construction, nuclear power, ocean development, medical care and services.' Mr Inaba adds: 'Strenuous research and development efforts for high technologies are essential to meeting such a wide range of economic and social needs in Japan. Among 15 new and growth sectors covered by a government programme for economic restructuring and creation, pre-arrangements are being made for a research and development project on 'human co-operating and coexisting robots' for which the programme calls on interested parties to immediately set about development and commercialisation tasks. The robot industry intends to participate actively in the project when it comes to the implementation stage. "Thus the Japan Robot Association intends to carry out actively on various operations aimed at further development of the industry. For this purpose, we request the competent government agencies and other interested parties for continued guidance, assistance and cooperation' concludes Mr Inaba.

\section{UNITED KINGDOM}

\section{Record robot instaillations driven by autoindustry uses}

ROBOT installations in the United Kingdom in 1997 rose by a massive $60 \%$ compared with 1996 which was itself a record year. In 1996 out of a total of 1,116 installations, no less than 596 went into the automotive industry. In 1997 the total number of installations was declared as 1,792 of which no less than 1,274 went to the automotive industry and its suppliers, leaving 518 for the rest of UK industry. In other words, while international automotive companies in the UK have been forging ahead to create a world-class manufacturing base, the rest of the UK has remained static, according to the British Robot Association. Within the total of the 518 which went to the rest of the UK industry, there has been some ups and downs, but as the numbers involved are relatively small this plays havoc with producing meaningful statistics or trends. As Mike Wilson, President of the BRA said, 'These changes are more likely to be minor bips resulting from installations just before or just after the cutoff dates, rather than major swings within industries. 'By far the largest number of machines installed in the UK in 1997 originated from Japan. The number totalled 867. The BRA does not break down the figures further to reveal robot by manufacture, but it has to be assumed that many of these machines were built by Kawasaki and Fanuc. The Japanese contingent was followed by robots from the European community with 739 machines. These included machines from ABB Flexible Automation, Comau and KUKA. Machines built in the UK totalled 141, leaving 41 to be sourced from the rest of the world. One encouraging fact that emerges from closer examination of the automotive industry figures is how growing acceptance of robots is moving down the supply chain. Within the total figures, automotive component manufacturers accounted for 215 robots installed in 1996 and 442 in 1997. The figure for mainstream automotive assemblers can fluctuate widely depending on new model changes. A single order can account for over 250 robots. It is a different picture for component suppliers because here the orders are generally smaller and more numerous. Component suppliers tend, to some extent, to mirror what is happening at vehicle assemblers, but the total is made up of many orders from a large number of large companies. This suggests a wide, across-the-board acceptance of the technology. As Wilson explained: 'This is both positive and not entirely surprising. Many competent suppliers are part of international groups that have a wider acceptance of robots than the rest of industry. They are also under constant pressure from the automotive industry to minimise cost and maximise quality. Installing robots can address both of these criteria. 'Accord- 
ing to the BRA the picture from the rest of UK industry is much more gloomy; nevertheless, there are some chinks of light. The generally static figure for the rest of UK industry reflects the growing concerns of many commentators that the UK is reluctant to invest in new technology; yet investment in automation is essential if the Government's objective of improving the UK's manufacturing base is to be achieved. Looking at UK figures from the viewpoint of robot applications reveals, as expected from previous years' figures, that spot welding (866) and arc welding (271) dominate the returns from industry, reflecting the main areas of robot use within the automotive industry. Water jet and laser cutting applications increased from three in 1996 to 27 in 1997, signalling perhaps a wider acceptance of new production technologies. On the other hand, one area which has seen growth in recent years - the plastics industry recorded a downturn. Installations here fell from 288 in 1996 to 232 in 1997. One bright spot which augers well for the future - albeit from a low base - is education and research. Here installation rose from 4 in 1996 to 27 in 1997. Two areas associated with parts movement also increased. Handling and palletising increased from 88 to 94 while machine tool loading rose much more dramatically from 67 to 99. European Union legislation in recent years has laid down recommendations for the maximum loads that can be handled manually and this may have impacted on sales in this area. Also, within the automotive industry there has been increased application for robots for inter-machine handling on large presses, as well as loading much larger components such as gearboxes and aluminium wheels by means of robots. All BRA figures are forwarded to the International Federation of Robotics (IFR) where they are collated with those from all the major industrialised countries to produce a set of world-wide statistics. The IFR, in collaboration with the Economic Commission for Europe, a United Nations organisation, produces what is without doubt the most telling statistics of all - robot density per 10,000 people employed in manufacturing industry. The UK, with a figure of 18.9 , ranks sixteenth behind Spain, Norway and Australia. The league is topped by Japan with a figure of 264.3. The UK robot density per employee is half that of the USA - 37.9. Perhaps of more relevance are the numbers relating to the UK's European partners. Germany, Italy and France have figures of 79.3, 56 and 36.4 respectively. The figure of 18.9 per 10,000 employees has to improve dramatically if the UK is to be considered as a truly first division manufacturer. Forecasts from the IFR predict that the year will see the one millionth robot installed. 'But will there be enough of them in the UK?' asks Mike Wilson. 